\title{
Research on Relationship between Port Logistics and Economic Growth Based on VAR: A Case of Shanghai
}

\author{
Jiahui Sun, Siqin Yu \\ School of Economics and Management, Shanghai Maritime University, Shanghai, China \\ Email: btixiaoding@126.com
}

How to cite this paper: Sun, J.H. and Yu, S.Q. (2019) Research on Relationship between Port Logistics and Economic Growth Based on VAR: A Case of Shanghai. American Journal of Industrial and Business Management, 9, 1557-1567.

https://doi.org/10.4236/ajibm.2019.97102

Received: May 31, 2019

Accepted: July 15, 2019

Published: July 18, 2019

Copyright $\odot 2019$ by author(s) and Scientific Research Publishing Inc. This work is licensed under the Creative Commons Attribution International License (CC BY 4.0).

http://creativecommons.org/licenses/by/4.0/

\begin{abstract}
This paper considers the relationship between Shanghai port logistics and regional economic growth. Vector autoregression (VAR) model, Granger causality test, impulse response functions(IRF) are used based on the statistical data of Shanghai for the years from 1990 to 2017. The results indicate a long-term equilibrium relationship among variables. Besides, cargo throughput and container throughput, the chosen indexes to study port logistics exist a bidirectional causality. Cargo throughput is unidirectionally causal to economic growth.
\end{abstract}

\section{Keywords}

Port Logistics, Economic Growth, VAR, Shanghai

\section{Introduction}

As transportation hubs, ports play the important roles in the connection between water and land as well as supporting foreign trade. Integrating modern information and infrastructure, ports provide logistics activities to hinterlands. Port logistics expands the traditional warehousing and transportation functions of the port. Coordinating services such as warehousing, transportation, loading and unloading, distribution, packaging, processing, and shipping documents, port logistics activities extend the value chain of the port supply chain [1], and it can also drive the development of industry and commerce of the hinterland, which stimulates employment increase and promotes the upgrading of industrial structure. Considering the relationship between port logistics development and regional economic growth can measure the status of port logistics in the regional economy, and the interaction and mutual promotion of port logistics and re- 
gional economy can achieve common development.

Shanghai Port is one of the most important ports in China, and it is an important engine in economic growth for Shanghai and surrounding areas. With the development of the Shanghai International Shipping Center and the continuous expansion of the services and functions of Shanghai Port, the construction of the Shanghai Port Logistics System has gradually become a focus. At present, most of the research in the relationship between Shanghai Port Logistics and the regional economy is based on qualitative analysis, and there is still no quantitative analysis of the relationship between the two and the degree of mutual influence.

In this paper, we try to use quantitative analysis method to research the relationship between Shanghai's economic growth and port logistics, which provides better reference for the former qualitative research. Actually, the quantitative method is insufficient in the research for the relationship of economic growth and port logistics in Shanghai. Selecting the statistical data of Shanghai from 1990 to 2017, we try to establish a vector autoregression (VAR) model. Granger causality test and impulse response analysis (IRF) are also used to study the relationship between regional economic growth and port logistics.

Because of the limitation of objective factors such as lacking special index of measure the port logistics, the substituted indicators we choose may not represent the development of port logistics in Shanghai precisely. Furthermore, in the context of the global supply chain, the complexity of the international political and economic situation such as Sino-US trade war may contribute to a complicated influence for port industry and regional economy, which also affect the accurateness of our research.

This paper is organized as follows: Section 1 introduces the purpose and importance of researching for relevance between economic growth and port logistics in Shanghai. Section 2 gives a brief overview of research for the relationship between economic growth and port logistics. Section 3 considers the introduction for choosing econometric model and variables, including preliminary processing of data. Based on Section 3, a vector autoregression model through variables is built and we try to apply Granger causality test and impulse response analysis to analyze the empirical results. A conclusion and suggestions are given in Section 5.

\section{Economic Growth and Port Logistics: Literature Review}

In the context of global supply chains, ports have become important core in the supply chain for a country or region, so studying the relationship between ports and regional economies is necessary. In the relationship between the port and the city, many scholars have conducted research. Dong and Liu (2008) analyzed the diffusion effect and multiplier effect of regional economic growth, and proposed the coordinated development model of the port logistics and the regional economy [2]. Shen and Yang (2012) considered the synergy of regional logistics 
with port logistics by using qualitative and quantitative analysis methods, and analysed the influence upon the regional economy. The empirical analysis found out that the interactive relationship between port logistics and regional economic development in the Pearl River Delta [3].

$\mathrm{Wu}$ (2012) qualitatively analyzed the collaborative relationship of port and area economy, and investigated the degree measurement model between those. The result found out that the synergy measurement model can reflect the level of joint development of Liaoning coastal economic zone [4]. Zhang and Ning (2012) used the data of Hebei province in GDP and port throughput from the year 1990 to 2010 and built grey relational analysis. The result proved port logistics and economic growth have close correlation [5]. Deng (2010) found the relevance of regional economy and port logistics under the circumstance of the regional economic growth theory. Based on empirical analysis, the paper measured the degree of relevance in five coastal ports of China [6]. Lv and Tang (2012) expounded the interrelationship between the port logistics and regional economy and analyzed the relativity between Chongqing port logistics and economy based on the grey synthetically relational degree, which revealed that the two indexes are highly relative. According to the level of coordination between the two aspects using the multi-dimension grey GM $(1, \mathrm{~N})$ mode, they found that Chongqing port logistics and economic are coordinate as a whole system and have a certain development ability, but there are some un-cooperative factors between them [7].

Xie (2011) measured the relationship between Shandong port logistics and economic development. He found that there is a long-term equilibrium relationship between Shandong port logistics and regional economic development, and economic development promotes the development of port logistics [8]. $\mathrm{Xu}$ and $\mathrm{Li}$ (2015) formulated a synergy degree model for the relationship between logistic of Chongqing Free Trade Port Area and regional economic. The finding of which demonstrated that the development of two subsystems are synergistic, and it provided some references for Chongqing bonded port area to improve the collaborative development level of multi-system [9].

It can be seen from the existing literature that the relationship between port logistics and economic growth is different for different regions, and the degree of mutual influence is also different. With the variety of global trading trend, economy in different countries or regions is changing frequently and the mutual influence between port logistics and economy is becoming more and more complex. There is an obvious theoretical and practical significance in the research for the relevance between port logistics and economic growth, so this problem is still worth studying.

\section{Econometric Models}

\subsection{VAR Method}

The vector autoregression (VAR) model is a model that is constructed by using 
each endogenous variable in the system as a function of the hysteresis value of all endogenous variables of the system. It is quite often applied to predicting the interconnected system and analyze the dynamic impact of random disturbances on the variable system, and it is available to explain the impact of economic variables on economic shocks [10].

A VAR model can be applied to study the relationship between different variables when those variables show significant characteristic of time series. Tao (2012) and Zhang (2014) constructed vector auto-regression model and system dynamics methodology to analyze causality of regional GDP, employment and transportation analysis in Dalian, and the results show that there are long-term equilibrium relationship and interaction in port logistic and regional economy [11] [12]. Chen (2015) used the vector auto-regression model to study the interaction between economic growth and port logistics of the city and found that there existed a bi-way causality between port throughput and container throughput and that these two indexes were unilaterally causal to economic growth while the contribution of container throughput was more pronounced [13]. Based on the feature of data, VAR method can be expanded to panel vector autoregression (PVAR), global vector autoregression (GVAR) and time verifying vector autoregression (TVAR), such as Gabriel and Ribeiro (2019) investigated how manufacturing affects economic growth over time using panel vector autoregression [14].

This paper aims to measure the relationship between the regional economy and port logistics in Shanghai. It is considered that the pre-selected indicators have obvious time series characteristics, and each variable is affected by itself and other variables in the current period as well as the previous periods. Therefore, the VAR model is used to the relationship between Shanghai port logistics and economic growth is analyzed. The basic form of the VAR model is as follows:

$$
y_{t}=a_{1} y_{t-1}+a_{2} y_{t-2}+\cdots+a_{p} y_{t-p}+b x_{t}+\mu_{t}
$$

where

$$
\begin{aligned}
& y_{t} \text { is endogenous vector, } \\
& x_{t} \text { is exogenous vector, } \\
& \mu_{t} \text { is disturbance vector, } \\
& a_{1}, \cdots, a_{p} \text { and } b \text { is estimated coefficient matrix. }
\end{aligned}
$$

\subsection{Data Processing}

One of the most notable indicators of economic development is the gross regional product (GDP). As an important index for measuring the total amount of the economy, GDP can better represent the scale of the country's economic volume and can measure economic changes. Port logistics is a relatively new problem. There is still no unified definition and no specific statistical indexes. As a system, port logistics is the integration of many logistics services, which can provide goods, funds and information services, and the services are mainly 
around the goods. Therefore, port cargo throughput and container throughput can be selected as indicators to measure port logistics development.

In order to study the relationship between Shanghai's regional economy and port logistics, we select Shanghai GDP (SGDP) index to measure Shanghai's economic development, Shanghai Port Container Throughput (SJ) and cargo throughput (SH) as the indexes for measuring port logistics in 1990-2017. We choose the natural logarithm of three indexes to eliminate the effects of heteroscedasticity and dimension, and the processed variables are recorded as LNSGDP, LNSH and LNSJ. Table 1 gives the statistical values of Shanghai's GDP, port cargo throughput and container throughput from 1990 to 2017 after natural logarithm processing.

The indicators we selected are typical time series. Exploring the characteristics of time series helps to further process, thus after the non-dimensionalization of data, we try to analyze the statistical characteristics of the indicators. Table 2 shows Descriptive statistics.

A set of quantifiable time series usually has a time trend and instability. It is easy to generate pseudo-regression risk when performing regression analysis on non-stationary time series. To eliminate pseudo-regression, the unit root test is used to test the stability of variables. Non-stationary time series can be adjusted by making the first-order difference of the time series. If the first-order difference sequence is still not a stationary sequence, the second-order difference can be performed. Table 3 shows the unit root test results of each variable.

As is shown in Table 3, the ADF value of LNSH is greater than the critical values corresponding to the $1 \%$ and $5 \%$ test levels, so the null hypothesis cannot

Table 1. Processing result of LNSGDP, LNSJ and LNSH, 1990-2017.

\begin{tabular}{cccccccc}
\hline \multirow{2}{*}{ Year } & \multicolumn{3}{c}{ Variable } & & & \multicolumn{3}{c}{ Variable } \\
\cline { 2 - 3 } \cline { 7 - 8 } & LNSGDP & LNSH & LNSJ & & LNSGDP & LNSH & LNSJ \\
\hline 1990 & 6.6280 & 9.5439 & 3.8286 & 2004 & 8.9160 & 10.5426 & 7.2828 \\
1991 & 6.7957 & 9.5942 & 4.0604 & 2005 & 9.1209 & 10.6991 & 7.5000 \\
1992 & 7.0157 & 9.6987 & 4.2905 & 2006 & 9.2396 & 10.8921 & 7.6834 \\
1993 & 7.3205 & 9.7754 & 4.5433 & 2007 & 9.3927 & 10.9357 & 7.8690 \\
1994 & 7.5868 & 9.7160 & 4.7875 & 2008 & 9.5250 & 10.9711 & 7.9377 \\
1995 & 7.8091 & 9.7152 & 5.0304 & 2009 & 9.6092 & 10.9888 & 7.8240 \\
1996 & 7.9732 & 9.7051 & 5.2832 & 2010 & 9.7507 & 11.0873 & 7.9749 \\
1997 & 8.1197 & 9.7049 & 5.5334 & 2011 & 9.8625 & 11.1949 & 8.0627 \\
1998 & 8.2128 & 9.7042 & 5.7268 & 2012 & 9.9125 & 11.2058 & 8.0873 \\
1999 & 8.3028 & 9.8331 & 6.0450 & 2013 & 9.9805 & 11.2590 & 8.1203 \\
2000 & 8.4231 & 9.9252 & 6.3297 & 2014 & 10.0673 & 11.2323 & 8.1662 \\
2001 & 8.5073 & 10.0033 & 6.4520 & 2015 & 10.1252 & 11.1808 & 8.2033 \\
2002 & 8.5958 & 10.1805 & 6.7581 & 2016 & 10.2463 & 11.1588 & 8.2196 \\
\hline & 8.7405 & 10.3616 & 7.0282 & 2017 & 10.3298 & 11.2259 & 8.2998 \\
\hline
\end{tabular}

Source: Shanghai statistical yearbook and author calculated. 
Table 2. Descriptive statistics, 1990-2017.

\begin{tabular}{cccc}
\hline & LNSGDP & LNSH & LNSJ \\
\hline Mean & 8.789624 & 10.42984 & 6.676013 \\
Median & 8.828233 & 10.45210 & 7.155481 \\
Maximum & 10.32983 & 11.25900 & 8.299783 \\
Minimum & 6.628041 & 9.543880 & 3.828641 \\
Std. Dev. & 1.103350 & 0.659504 & 1.490258 \\
Skewness & -0.363805 & -0.009629 & -0.549488 \\
Kurtosis & 2.040676 & 1.265426 & 1.852740 \\
Jarque-Bera & 1.691339 & 3.510636 & 2.944611 \\
\hline
\end{tabular}

Table 3. Unit root tests, 1990-2017.

\begin{tabular}{ccccc}
\hline Variable & ADF & $\begin{array}{c}1 \% \text { Critical } \\
\text { Value }\end{array}$ & $\begin{array}{c}5 \% \text { Critical } \\
\text { Value }\end{array}$ & p-value \\
\hline LNSGDP & $-4.867064^{* * *}$ & -3.699871 & -2.976263 & 0.0006 \\
LNSJ & $-4.950277^{* * *}$ & -3.699871 & -2.976263 & 0.0005 \\
LNSH & -0.779590 & -3.711457 & -2.981038 & 0.8083 \\
DLNSGDP & -1.815209 & -3.711457 & -2.981038 & 0.3652 \\
DLNSJ & -2.200736 & -3.711457 & -2.981038 & 0.2107 \\
DLNSH & -2.411703 & -3.711457 & -2.981038 & 0.1484 \\
DDLNSGDP & $-5.338505^{* * *}$ & -3.724070 & -2.986225 & 0.0002 \\
DDLNSJ & $-6.633921^{* * *}$ & -3.737853 & -2.991878 & 0.0000 \\
DDLNSH & $-5.788228^{* * *}$ & -3.724070 & -2.986225 & 0.0001 \\
\hline
\end{tabular}

Note: ADF with trend and intercept. Lags selection by Akaike Information Criterion (AIC). ${ }^{* * *}$ indicates significant at $1 \%$ level. D indicates first order difference. DD indicates second order difference.

be rejected. The original sequence has unit roots, which is a non-stationary sequence. After the first-order difference of original sequences, the ADF values of DLNSGDP, DLNSH and DLNSJ are greater than the critical values of $1 \%$ and $5 \%$ test levels, which are unstable sequences. After the second-order difference, the ADF values of three variables are less than the critical value of the $1 \%$ and $5 \%$ test levels, which indicate that sequences reject the null hypothesis, and the second-order difference sequences are stable. Therefore, the variables become second-order single-order sequences, and there may be a cointegration relationship.

\section{Empirical Results}

\subsection{VAR Method}

After the unit root tests of indicators, we find that the original data are not stationary sequences. Despite the traditional VAR model requires stationary of each sequence, with the development of cointegration theory, non-stationary sequences can also directly used in VAR models, as long as there is a cointegration relationship among the variables. In order to reflect the practical signific- 
ance of the relationship among variables, we consider using non-stationary original sequences to establish a VAR model, and verifying the cointegration relationship later.

Before constructing the VAR model, we should define the lag order of the VAR model at first. Using the AIC, SC, and HQ criteria, we determine the lag order of the model to 1, thus VAR(1) model is established and shown in Table 4.

We consider the robustness of VAR(1) model. Robustness test is one of the important tests for the establishment of the model. The robustness test for the VAR model is performed by calculating the eigenvalues of the eigenvectors of the model. The necessary and sufficient condition for the stability of the VAR model is that the eigenvalues of the model should all be within the unit circle, or the eigenvalues should be less than 1, (i.e. within the unit circle). After determining the number of variables and the lag order of the model is 3 and 1 respectively, we obtain a feature vector $(3 \times 3)$ of the model. The calculated eigenvalues are $0.97,0.97$ and 0.94 , which are less than 1 (or within the unit circle). The results mean that the model passes the robustness test and the model is stable.

\subsection{Cointegration Test}

After constructing a stable VAR(1) model, we verify whether there is a cointegration relationship among the variables in the model, which is the key to the establishment of the $\operatorname{VAR}(1)$ model. The cointegration test is used to test whether the non-stationary time series has a long-term equilibrium relationship. Using cointegration test, we can avoid the possible pseudo-regression problem. In this paper we use Johansen Cointegration test. Table 5 shows the results of the cointegration test.

Table 4. VAR estimation results.

\begin{tabular}{cccc}
\hline & LNSGDP & LNSH & LNSJ \\
\hline LNSGDP(-1) & 0.882523 & -0.212918 & -0.057954 \\
& $(0.04434)$ & $(0.05793)$ & $(0.07049)$ \\
& {$[19.9046]$} & {$[-3.67543]$} & {$[-0.82220]$} \\
\hline LNSH(-1) & 0.106654 & 0.874460 & -0.206475 \\
& $(0.03964)$ & $(0.05179)$ & $(0.06301)$ \\
\hline LNSJ(-1) & {$[2.69089]$} & {$[16.8860]$} & {$[-3.27685]$} \\
& 0.011556 & 0.207451 & 1.075164 \\
& $(0.03211)$ & $(0.04196)$ & $(0.05105)$ \\
\hline C & {$[0.35986]$} & {$[4.94422]$} & {$[21.0601]$} \\
\hline R-squared & -0.022715 & 1.854811 & 2.321818 \\
Adj. R-squared & $(0.30918)$ & $(0.40397)$ & $(0.49152)$ \\
S.E. equation & {$[-0.07347]$} & {$[4.59149]$} & {$[4.72372]$} \\
Log likelihood & 0.998592 & 0.993836 & 0.998065 \\
\hline
\end{tabular}


Table 5. Cointegration test results.

\begin{tabular}{|c|c|c|c|c|c|c|c|c|c|}
\hline Hypothesized & \multirow{2}{*}{ Eigenvalue } & \multirow{2}{*}{$\begin{array}{c}\text { Trace } \\
\text { Statistic }\end{array}$} & \multirow{2}{*}{$\begin{array}{c}5 \% \\
\text { Critical } \\
\text { Value }\end{array}$} & \multirow{2}{*}{ Prob. ${ }^{* *}$} & \multirow{2}{*}{$\begin{array}{l}\text { Hypothesized } \\
\text { No. of CE(s) }\end{array}$} & \multirow{2}{*}{ Eigenvalue } & \multirow{2}{*}{$\begin{array}{c}\text { Max-Eigen } \\
\text { Statistic }\end{array}$} & \multirow{2}{*}{$\begin{array}{c}5 \% \\
\text { Critical } \\
\text { Value }\end{array}$} & \multirow{2}{*}{ Prob.** } \\
\hline No. of $\mathrm{CE}(\mathrm{s})$ & & & & & & & & & \\
\hline None ${ }^{*}$ & 0.736015 & 63.29347 & 29.79707 & 0.0000 & None $e^{*}$ & 0.736015 & 33.29655 & 21.13162 & 0.0006 \\
\hline At most $1^{*}$ & 0.523777 & 29.99692 & 15.49471 & 0.0002 & At most $1^{*}$ & 0.523777 & 18.54670 & 14.26460 & 0.0099 \\
\hline At most $2^{*}$ & 0.367458 & 11.45022 & 3.841466 & 0.0007 & At most $2^{*}$ & 0.367458 & 11.45022 & 3.841466 & 0.0007 \\
\hline
\end{tabular}

Note: ${ }^{* *}$ indicates significant at $5 \%$ level.

From Table 5, the results indicate that there is a cointegration relationship among LNSGDP, LNSJ and LNSH at a significant level of 5\%, which represents that there is a long-term equilibrium relationship among LNSGDP, LNSJ and LNSH, and confirms the effectiveness of VAR(1) model we built. According to Table 4, we find that cargo throughput and container throughput have positive effects on GDP. 1\% increase in cargo throughput can boost GDP growth by $0.11 \%$, and $1 \%$ increase in container throughput can drive GDP growth by $0.012 \%$, which is not obvious. Container throughput has a positive effect on cargo throughput, because $1 \%$ increase in container throughput can drive a $0.21 \%$ increase in cargo throughput.

\subsection{Granger Causality}

In this section, we analyze the relationship among variables by using Granger causality test. Granger causality test can be used to test whether the lag term of a variable in the vector autoregression model affects the current value of other variables, that is, forecast the causal relationship between the variables. The unit root test shows that the variables selected in this paper are unstable sequences, but after passing the cointegration test, the Granger causality test is still worked, and the results are still valid. Table 6 gives the Granger causality test results.

Determining the cointegration relationship of variables, we try to find the relationship among regional GDP, port cargo throughput and container throughput in Shanghai based on VAR model. The results show a unidirectional causality from cargo throughput to GDP in Shanghai and bidirectional causality between cargo throughput and container throughput.

\subsection{Impulse Response Functions}

We have already discussed the causal relationship between variables. In this section, we analyze the degree of interaction among variables, that is, whether variables respond to changes of other variables. We use the impulse response function (IRF) for analysis, which refers to the change of the current value and the future value when a variable is impacted by a standard deviation of the system. The impulse response function graph of the variable is obtained by using the Eviews 10 software, and Figures 1-3 show the results of the impulse response analysis. 
Table 6. Granger causality tests.

\begin{tabular}{cccc}
\hline Null Hypothesis & F-Statistic & Prob. & Inference \\
\hline LNSH does not Granger Cause LNSGDP & 8.53523 & 0.0075 & LNSH $\rightarrow$ LNSGDP \\
LNSGDP does not Granger Cause LNSH & 0.53577 & 0.4713 & No causality \\
LNSJ does not Granger Cause LNSGDP & 0.88429 & 0.3564 & No causality \\
LNSGDP does not Granger Cause LNSJ & 2.23184 & 0.1482 & No causality \\
LNSJ does not Granger Cause LNSH & 7.88568 & 0.0097 & LNSJ $\rightarrow$ LNSH \\
LNSH does not Granger Cause LNSJ & 13.3798 & 0.0012 & LNSH $\rightarrow$ LNSJ \\
\hline
\end{tabular}

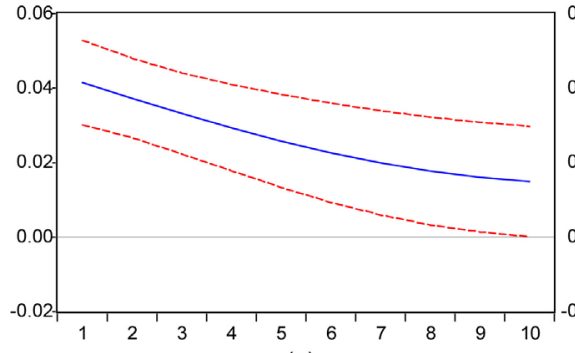

(a)

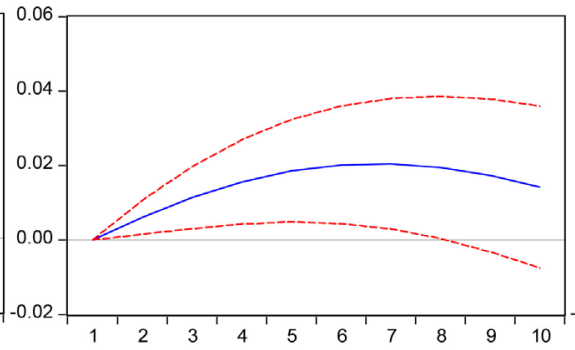

(b)

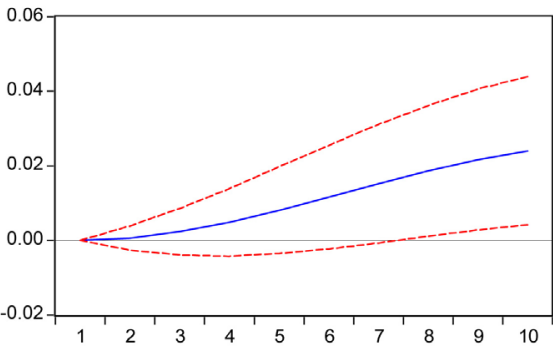

(c)

Figure 1. Impulse-response functions of LNSGDP for 10 periods. (a) Response of LNSGDP to LNSGDP. (b) Response of LNSGDP to LNSH. (c) Response of LNSGDP to LNSJ.

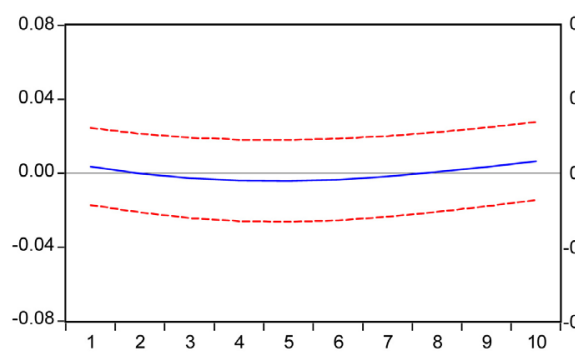

(a)

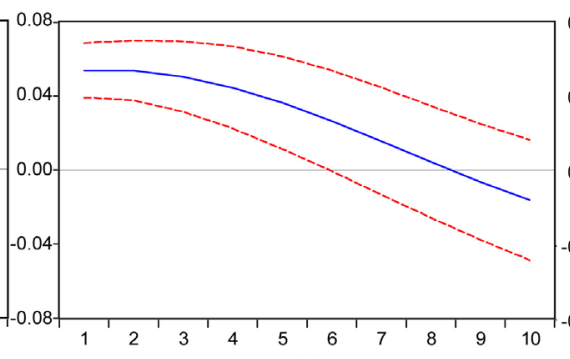

(b)

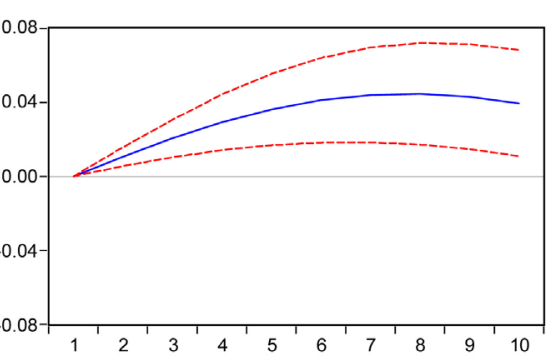

(c)

Figure 2. Impulse-response functions of LNSH for 10 periods. (a) Response of LNSH to LNSGDP. (b) Response of LNSH to LNSH. (c) Response of LNSH to LNSJ.

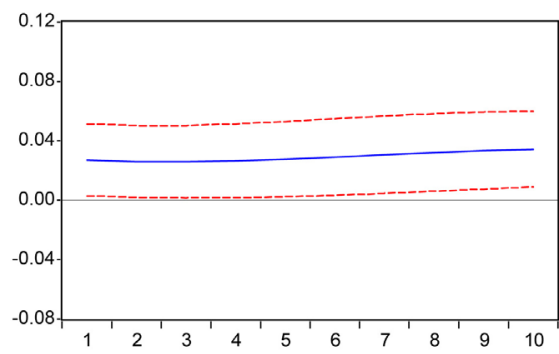

(a)

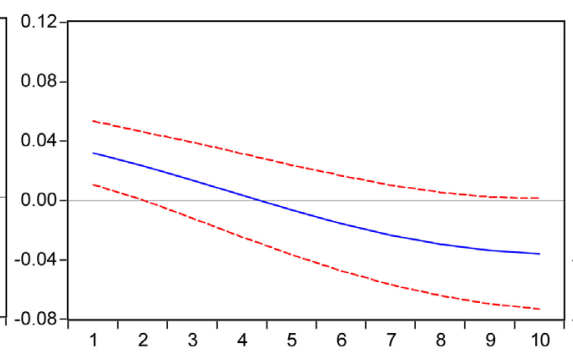

(b)

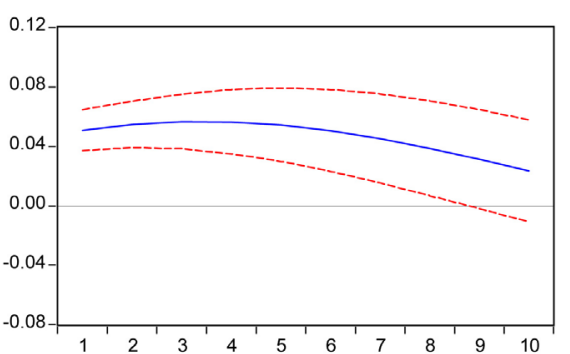

(c)

Figure 3. Impulse-response functions of LNSJ for 10 periods. (a) Response of LNSJ to LNSGDP. (b) Response of LNSJ to LNSH. (c) Response of LNSJ to LNSJ.

In Figures 1-3, the solid lines indicate the cumulative impulse response function after the impact, and the dotted lines indicate the positive and negative standard deviation bands. The horizontal axis represents the number of lag pe- 
riods after the impact, and the vertical axis means the intensity of the impulse response function after the impact. Figure 1(b) shows that the positive impact of Shanghai port cargo throughput in the current period will lead to the growth of Shanghai GDP, and reach the maximum between the sixth and seventh periods, and then decline slowly. The result indicates that cargo throughput brings the same impact to GDP, and the effect last longer. Figure 1(c) shows the positive impact of Shanghai port container throughput in the current period will lead to an increase in GDP, and the effect will continue to strengthen and last during observation periods.

Figure 2(a) shows that the positive impact of Shanghai's GDP in the current period will lead to an increase in cargo throughput, but the effect is weak. Figure 2 (c) indicates that the positive impact of Shanghai port container throughput during current period will lead to an increase in cargo throughput, and the impact reaches a maximum in the period of 7 th to 8 th and then decline slowly, which indicate the same direction between the two variables. The change is positive and the effect is strong.

Figure 3(a) shows that impact of Shanghai's GDP in the current period will lead to an increase in Shanghai's container throughput, and the effect is stable and lasts longer. Figure 3(b) indicates the impact of the Shanghai port cargo throughput on the current period will cause the container throughput to be positively impacted (period1-period4), but the effect is gradually weakened and becomes a reverse shock in the fifth period.

\section{Conclusion}

In our study, VAR model and related test methods are used to empirically analyze the relationship between Shanghai port logistics and economic growth. The results show that there is a long-term equilibrium relationship among port cargo throughput and container throughput, which are selected to measure the port logistics of Shanghai, and GDP index which is used to measure Shanghai's regional economic growth. The effect of port container throughput on economic growth is not significant, but the growth of port cargo throughput can significantly promote economic growth. There is a unidirectional causality between cargo throughput and GDP. These results show that port logistics development is an important engine for Shanghai's economic growth. Port cargo throughput and container throughput interact with each other and have a bidirectional causality, which shows the interaction within the various systems of port logistics.

Considering the accelerating position of port logistics on Shanghai's economic growth, Shanghai should make full use of the policy advantages of international shipping center and free trade zone, grasp the trend of supply chain synergistic development, broaden the scope of port logistics services, play the roles in the radiation effect and promote the economic development.

\section{Conflicts of Interest}

The authors declare no conflicts of interest regarding the publication of this paper. 


\section{References}

[1] Shen, Q. (2013) Research on the Relationship between Port Logistics and Urban Economic Growth: A Case Study of Dalian. Master's Thesis, Liaoning Normal University, Dalian.

[2] Dong, M.W. and Liu, M.M. (2008) The Research of the Coordinated Development Model between Port Logistics with the Regional Economy. Storage Transportation \& Preservation of Commodities, 8, 10-11.

[3] Shen, X. and Yang, F. (2010) Empirical Analysis on Coordinated Development of Port Logistics and Regional Economic in the Pearl River Delta. Logistics Sci-Tech, 2, 67-71.

[4] Wu, Y. (2012) Research on the Coordination Degree between Port Logistics and Regional Economy in Liaoning Coastal Economic Zone. Master's Thesis, Dalian Maritime University, Dalian.

[5] Zhang, J. and Ning, L.L. (2012) Gray Correlation between Port Logistics and Regional Economy. Logistics Sci-Tech, 7, 6-10.

[6] Deng, P. (2010) The Research of Relevance Measure between Port Logistics and Hinterland Region Economics. Master's Thesis, Wuhan University of Technology, Wuhan.

[7] Lv, Q. and Tang, Q. (2012) Coordinate Development of Port Logistics and Regional Economy. Port \& Waterway Engineering, 4, 67-70.

[8] Xie, J. (2011) Research on the Relationship between Shandong Port Logistics and Regional Economic Development. Shandong Social Sciences, 3, 174-176.

[9] Xu, L.L. and Li, W. (2015) Research on Synergetic Development between Logistic of Chongqing Free Trade Port Area and Regional Economy. Journal of Chongqing University of Technology (Social Science), 29, 22-26.

[10] Gao, T. (2005) Econometric Analysis Methods and Modeling-Reviews Applications and Examples. Tsinghua University Press, Beijing.

[11] Tao, Y. (2012) The Research of Interactive Relationship between Port Logistics and Urban Economic Development. Master's Thesis, Dalian Maritime University, Dalian.

[12] Zhang, X. (2014) The Relationship between Port Logistics and Regional Economy. Master's Thesis, Dalian Maritime University, Dalian.

[13] Chen, Z.L. (2015) Empirical Analysis of Relationship between Port Logistics and Economic Growth of Ningbo Based on VAR Model. Logistics Sci-Tech, 34, 154-157.

[14] Gabriel, L.F. and de Santana Ribeiro, L.C. (2019) Economic Growth and Manufacturing: An Analysis Using Panel VAR and Intersectoral Linkages. Structural Change and Economic Dynamics, 49, 43-61. https://doi.org/10.1016/j.strueco.2019.03.008 